\title{
Provisional Guideline Recommendation for EGFR Gene Mutation Testing in Liquid Samples of Lung Cancer Patients: A Proposal by the Korean Cardiopulmonary Pathology Study Group
}

Dong Hoon Shin · Hyo Sup Shim ${ }^{1}$ Tae Jung Kim ${ }^{2} \cdot$ Heae Surng Park ${ }^{3}$ Yun La Choi . Wan Seop Kim ${ }^{5}$ Lucia Kim ${ }^{6} \cdot$ Sun Hee Chang ${ }^{7}$ Joon Seon Song ${ }^{8} \cdot$ Hyo Jin Kim ${ }^{9}$ Jung Ho Han ${ }^{4}$. Chang Hun Lee Geon Kook Lee ${ }^{10} \cdot$ Se Jin Jang ${ }^{8}$ Korean Cardiopulmonary Pathology Study Group

Department of Pathology, Pusan National University School of Medicine, Yangsan; 'Department of Pathology, Yonsei University College of Medicine, Seoul; ${ }^{2}$ Department of Hospital Pathology, College of Medicine, The Catholic University of Korea, Seoul; ${ }^{3}$ Department of Pathology, Ewha Womans University Mokdong Hospital, Seoul; ${ }^{4}$ Department of Pathology, Samsung Medical Center, Sungkyunkwan University School of Medicine, Seoul; ${ }^{5}$ Department of Pathology, Konkuk University School of Medicine, Seoul; ${ }^{6}$ Department of Pathology, Inha University School of Medicine, Incheon; 'Department of Pathology, Inje University Ilsan Paik Hospital, Inje University College of Medicine, Goyang; ${ }^{8}$ Department of Pathology, Asan Medical Center, University of Ulsan College of Medicine, Seoul; ' ${ }^{9}$ Department of Pathology, Seoul National University Bundang Hospital, Seongnam; ${ }^{10}$ Department of Pathology, National Cancer Center, Goyang, Korea

Received: November 29, 2018

Revised: February 7, 2019

Accepted: February 20, 2019

Corresponding Author

Se Jin Jang, MD, PhD

Department of Pathology, Asan Medical Centre, University of Ulsan College of Medicine, 88 Olympic-ro 43-gil, Songpa-gu, Seoul 05505 , Korea

Tel: +82-2-3010-5966

Fax: +82-2-472-7898

E-mail: jangsejin@amc.seoul.kr
Liquid biopsy for detection of mutation from circulating tumor DNA is a new technology which is attractive in that it is non-invasive. Epidermal growth factor receptor (EGFR) tyrosine kinase inhibitors (TKI) is an effective first line drug for advanced non-small cell lung cancer patients who harbor activating EGFR mutation. During the course of treatment, resistance against TKI arises which can be contributed to EGFR T790M mutation in about $50-60 \%$ of patients. Third generation TKI may overcome the resistance. In patients who cannot undergo tissue biopsy due to variable reasons, liquid biopsy is an excellent alternative for the detection of EGFR T790M mutation. However, this relatively novel method requires standardization and vigorous quality insurance. Thus, a standard set of guideline recommendations for liquid biopsy for EGFR mutation testing suitable for the Korean medical community is necessary. In this article, we propose a set of provisional guideline recommendations that was discussed and approved by the Cardiopulmonary Pathology Study Group of the Korean Society of Pathologists.

Key Words: Carcinoma, non-small-cell lung; Epidermal growth factor receptor; T790M; Circulating tumor DNA; Liquid biopsy 
After the discovery of activating epidermal growth factor receptor (EGFR) gene mutation, EGFR tyrosine kinase inhibitors (TKI) became the first line of treatment in advanced non-small cell lung cancer (NSCLC) with mutated EGFR. ${ }^{1-3}$ These EGFR TKIs such as gefitinib, erlotinib, and afatinib show consistently better response rate and prolonged progression-free survival in EGFR mutant NSCLC patients. ${ }^{1-3}$ However, most patients receiving EGFR TKI treatment may develop acquired resistance. ${ }^{4-6} \mathrm{Al}-$ though various mechanisms are involved in this resistance, secondary T790M mutation of EGFR gene illustrates 50\%-60\% of the resistance. ${ }^{7,8}$ A recently developed third generation TKIs can effectively target T790M, and so it is very critical to detect this mutation in patients who has developed acquired resistance against first- or second-line EGFR TKIs. ${ }^{9-11}$

Liquid biopsy is an emerging tool that detects genetic changes in circulating tumor DNA (ctDNA) shed from the tumor cells. ${ }^{12-14}$ Recently, Cobas EGFR mutation test V2 (Roche, Indianapolis, IN, USA) has been approved by Food and Drug Administration (FDA) for the detection of EGFR mutations from the blood of NSCLC patients. ${ }^{15}$ Although this non-invasive technique is fascinating and promising, it is still a developing method which needs further improvements. Hence, it is necessary to have guidelines for its usage. Korean cardiopulmonary study group has prepared the first guideline of EGFR mutation detection in blood for clinicians and pathologists who actively take part in the diagnosis and treatment of lung cancer.

\section{PATIENT ELIGIBILITY}

Liquid biopsy for the detection of EGFR mutation can play many roles in cancer diagnostics. ${ }^{12-14,16,17}$ Patients diagnosed with lung adenocarcinoma harboring EGFR mutation will be the first candidates when they develop resistance against first-line TKIs. Especially, when the tumor is too small or located in a challenging region to be sampled, liquid biopsy can be a good alternative. ${ }^{14-18}$ Patients with poor performance status can also benefit from this technique.

\section{SAMPLE COLLECTION}

Sample collection and processing is a critical step in liquid biopsy. Since ctDNA is rapidly degraded by the nuclease in blood and contaminated by genomic DNA from blood cells, it is essential to separate plasma from the sample. ${ }^{13,14}$ The routine venipuncture technique will be sufficient to collect blood from the patients. The sample collection tube should be chosen considering each institution's setting. Conventional ethyldiaminetetraaceticacid (EDTA) tube can be used if the samples are processed without delay. ${ }^{19,20}$ Recently, specialized tubes for delaying degradation of ctDNA are commercially available. ${ }^{19,20}$ The tube from Streck (Omaha, NE, USA) has been the most widely used collection tube. Roche diagnostics and Qiagen have also marketed specialized tubes. According to a study, ${ }^{19}$ conventional EDTA tube and Streck tube do not show much difference in their performance when samples are processed within 6 hours. When incubated longer in EDTA tube, cell-free DNA may be released from the blood cells, and EDTA will hinder the polymerase chain reaction (PCR). ${ }^{20}$ Tubes from Roche and Qiagen showed similar performance, and they are slightly better than Streck tube. ${ }^{20}$ Specialized tubes can sustain sample quality for several days at room temperature before processing further (Table 1).

\section{CIRCULATING TUMOR DNA ISOLATION}

Before ctDNA extraction, blood should be processed into plasma through double centrifugation. Plasma samples are better than serum samples, which can be contaminated by DNA released from immune cells. ${ }^{13}$ Since a small amount of ctDNA is present in plasma, isolation is a critical step in the process for saving tumor DNA. Several commercial kits for isolation are available in the market (Table 2). ${ }^{21,22}$ These are manual, semiautomatic, and fully

Table 2. Commercially available ctDNA extraction kits

\begin{tabular}{llll}
\hline Company & Trade name & \multicolumn{1}{c}{ Method } & Automation \\
\hline ThermoFisher & MagMAX & Magnetic beads & Semiauto \\
Promega & Maxwell RSC & Magnetic beads & Semiauto \\
Roche & Cobas & Silica membrane & Manual \\
Qiagen & QIAamp & Silica membrane & Semiauto \\
\hline
\end{tabular}

ctDNA, circulating tumor DNA.

Table 1. Comparison of specialized tubes for collection of ctDNA

\begin{tabular}{|c|c|c|c|c|}
\hline Company & Trade name & Volume (mL) & Temperature $\left({ }^{\circ} \mathrm{C}\right)$ & Storage duration (day) \\
\hline Streck & cfDNA BCT & 10 & $6-37$ & 14 \\
\hline Roche & Cell-Free DNA Collection Tube & 8.5 & $18-25$ & 7 \\
\hline Qiagen & PAXgene Blood ccfDNA Tube & 10 & $18-25$ & 7 \\
\hline
\end{tabular}

ctDNA, circulating tumor DNA. 
automatic. Manual protocol uses column-based method while semi-automatic instrument works with magnetic beads. Previous studies showed variable results depending on the extraction kits, though they all had similar performances. ${ }^{21,22}$ The technician's skill and protocol optimization may be one of the critical factors for yielding better ctDNA. Table 1 summarizes commercial ctDNA extraction kits.

\section{MUTATION DETECTION METHODS}

High sensitivity detection methods are required to detect EGFR mutations from liquid samples. Kits for detecting mutations have been developed and are commercially available. ${ }^{23-25}$ Each kit requires different quality and amount of DNA (Table 3). They depend on real time PCR technology with their own variations. Roche Cobas uses real time PCR with Taqman like probe and Qiagen has released ARMS based kits, Therascreen EGFR RGQ. Another PCR based technique uses peptide nucleic acid clamping and Panamutyper (Panagene, Daejeon, Korea). The Roche and Qiagen systems use their own PCR machine from Roche and Qiagen while Panamutyper can run on any qualified PCR machines. The number of mutations these kits can detect are different; however, together they include exon 19 deletion, T790M and L858R. Currently, only Roche kit has acquired FDA approval. The most important element of these kits is how sensitively and specifically they can detect mutations in liquid samples. There are certain studies to evaluate their performance and report sensitivities ranging from $62 \%$ to $67.5 \%$ and specificities ranging from $88 \%$ to $97 \% .^{26-29}$ In the ASSESS study, these three kits showed high specificity, however, sensitivity was equal to or less than $75 \%$. $^{25}$ For T790M, sensitivity was $41 \%$ and $29 \%$ for Cobas and Therascreen, respectively, and specificity was $100 \%$ for both kits from the patients enrolled in AURA trial. ${ }^{10}$ Therefore, deciding the best kit will depend on the laboratory's choice with consideration of their requirements. Features of these products are summarized in Table 3. Other platforms using digital PCR and next generation sequencing are still far from widespread use in clinical setting. ${ }^{24}$

\section{REPORTING FORMAT}

Once liquid biopsy for detecting T790M mutation is done, the reports should contain the following information: pathologic number, age, sex, hospital unit number, sample source, requesting physician, requesting department, adequacy for testing (amount of DNA extracted), receipt day, report day, storage tube, methodology used, exons tested and associated range of detectable mutations, mutation status, comments, testing technician, and corresponding pathologist. Since the patients already have sensitizing EGFR mutation, it is recommended to include the type of original EGFR alteration and previous histologic diagnosis.

\section{PROPOSAL FOR AN EXTERNAL QUALITY ASSESSMENT PROGRAM}

Since liquid biopsy technique has not been validated yet, vigorous quality assurance is necessary. Although there is no recommended program for external quality assessment (EQA), one pilot trial for EGFR testing in blood is ongoing in Germany. ${ }^{30}$ Another program for BRAF and KRAS is also being conducted. ${ }^{31}$ Since patient derived standard sample is difficult to store and distribute, artificial sample mimicking the real one can be used instead. ${ }^{30,31}$ We are in the process of developing Korean EQA program.

\section{ROLE OF PATHOLOGISTS}

Performance and interpretation of liquid biopsy require broad knowledge in lung cancer pathology. Pathologists have an important role in the diagnosis and management of cancer and thus can interpret liquid biopsy results in conjunction with the histologic diagnosis, previous status of EGFR-activating mutation, and clinical situation. The liquid biopsy in lung cancer is usually performed in patients whose previous EGFR mutation status has been known. The sole purpose of this technique is to detect a T790M mutation responsible for TKI resistance. Unlike tissue specimens, in which the pathologists can determine the percentage of tumor

Table 3. EGFR mutation detection kits in plasma

\begin{tabular}{llll}
\hline Company & \multicolumn{1}{c}{ Trade Name } & \multicolumn{1}{c}{ Method } & \multicolumn{1}{c}{ Detectable mutations } \\
\hline Roche & Cobas & Real time PCR & EX19Del, S768I, T790M, L858R, L861Q, G719X, EX20Ins \\
Qiagen & Therascreen RGQ & ARMS & Ex19Del, T790M, L858R \\
Panagene & Mutyper & PNA clamp & EX19Del, S768I, T790M, L858R, L861Q, G719X, EX20Ins \\
Bio-Rad & rimePCR ddPCR Mutation Assay & Digital PCR & Ex19Del, T790M, L858R, L861Q \\
Sysmex-Inostics & OncoBEAM & Digital PCR & Ex19Del, T790M, L858R, C797S \\
\hline
\end{tabular}

EGFR, epidermal growth factor receptor; PCR, polymerase chain reaction; PNA, peptide nucleic acid. 
cells, it is extremely difficult to estimate whether the blood sample contains a sufficient amount of tumor DNA. If the sample is adequate, the test generally finds the original EGFR-activating mutation, which may act as an internal control for the presence of ctDNA. ${ }^{13}$ When it has not detected any EGFR-activating mutation including previously existing one or reported mutations other than the preexisting ones or $7790 \mathrm{M}$, pathologists should be able to interpret the result. In the former, test should be repeated because the samples might have been degraded and contain insufficient ctDNA. In the latter, the newly emerged mutation, in the presence of newly developed lesion, may indicate a metachronous primary tumor. The communication between pathologists, clinicians, and radiologists is important for further diagnosis and management of cancer. Moreover, lung adenocarcinoma undergoes frequent transformation into small cell carcinoma when it is treated with TKI, while maintaining the original EGFR mutation. ${ }^{7,832}$ Recommended interpretation is suggested in Table 4.

\section{PERSPECTIVES AND ADDITIONAL RECOMMENDATIONS}

EGFR mutation testing performed with blood or other liquid sample is a non-invasive method, which can be more widely adopted. Laboratories must get familiar with liquid samples and develop their own protocols to handle these specimens. They can choose appropriate sample tubes, extraction kits, detection methods, and other instruments. They should select the most suitable combination in accordance with their requirements, unless the detection kits indicate specific methods and instruments. ${ }^{31}$ Although sensitivity of tissue biopsy is higher than liquid biopsy, both are far from perfection and T790M mutation can be detected only in one of the two methods. Reportedly, allele fraction of T790M mutation tends to correlate with treatment efficacy of osimertinib. ${ }^{33}$ Therefore, absence of T790M in tumor tissue while it is detected in plasma might reflect low allele frequency and lead to poor response. Therefore, the two methods are complementary to each other and should be selected according to each patient's condition (Fig. 1).

\section{CONCLUSIONS}

Liquid biopsy is a promising method, which is safe and convenient. Before more experiences and data are accumulated, liquid biopsy should be performed with great caution. There are a few steps in liquid biopsy, which can produce false negative or false positive results. Interpretation requires profound knowledge of
Table 4. Recommended interpretation of EGFR mutation test from blood

\begin{tabular}{|c|c|c|}
\hline $\begin{array}{l}\text { Sensitizing } \\
\text { mutation }\end{array}$ & T790M & Interpretation \\
\hline Detected & Detected & $\begin{array}{l}\text { T790M positive: start treatment with } \\
\text { third generation TKI }\end{array}$ \\
\hline Detected & Not detected & $\begin{array}{l}\text { T790M negative: tissue biopsy } \\
\text { recommended }\end{array}$ \\
\hline Not detected & Detected & $\begin{array}{l}\text { T790M positive: confirmation is } \\
\text { necessary }\end{array}$ \\
\hline Not detected & Not detected & $\begin{array}{l}\text { Non-informative: tissue biopsy strongly } \\
\text { recommended }\end{array}$ \\
\hline
\end{tabular}

EGFR, epidermal growth factor receptor; TKI, tyrosine kinase inhibitor.

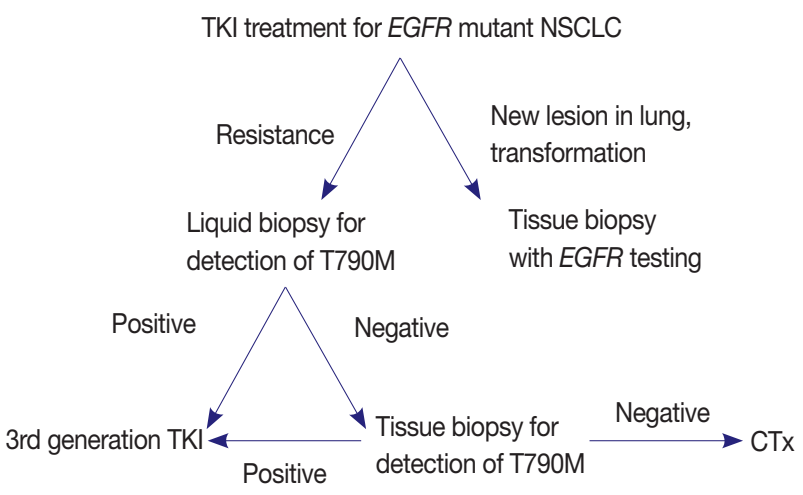

Fig. 1. Proposed diagnostic algorithm for the detection of epidermal growth factor receptor (EGFR) T790M mutation. NSCLC, nonsmall cell lung cancer; TKI, tyrosine kinase inhibitor; CTx, chemotherapy.

lung cancer including diagnosis, treatment, and prognosis. However, in debatable cases, discussion between pathologists, physicians, and radiologists is critical. This method will soon play a major role in early diagnosis, monitoring of treatment, and detection of minimal residual disease. Currently, it cannot replace the conventional pretreatment tissue diagnosis. ${ }^{14}$ It is important to validate and improve the performance of this technique before it is widely used in clinical practice. Liquid biopsy performed in $E G F R$ has provided a platform for determining gene mutations in KRAS, ALK, PI3CA, and BRAF as well.

\section{ORCID}

Dong Hoon Shin: https://orcid.org/0000-0002-4980-9295

Hyo Sup Shim: https://orcid.org/0000-0002-5718-3624

Tae Jung Kim: https://orcid.org/0000-0003-3140-3681

Heae Surng Park: https://orcid.org/ 0000-0003-1849-5120

Yun La Choi: https://orcid.org/0000-0002-5788-5140

Wan Seop Kim: https://orcid.org/0000-0001-7704-5942

Lucia Kim: https://orcid.org/0000-0002-4100-6607 
Sun Hee Chang: https://orcid.org/0000-0002-7775-4711

Joon Seon Song: https://orcid.org/0000-0002-7429-4254

Hyo Jin Kim: https://orcid.org/0000-0001-9201-8328

Jung Ho Han: https://orcid.org/0000-0003-4424-7008

Chang Hun Lee: https://orcid.org/0000-0003-4216-2836

Geon Kook Lee: https:/orcid.org/0000-0003-3138-3908

Se Jin Jang: https://orcid.org/0000-0001-8239-4362

\section{Author Contributions}

Conceptualization: DHS, HSS, TJK, HSP, YLC, WSK, LK, SHC, JSS, HJK, JHH, CHL, GKL, SJJ.

Data curation: DHS.

Formal analysis: DHS, HSS, TJK.

Investigation: DHS, HSP, YLC, WSK, LK.

Methodology: DHS, SHC, JSS, HJK, JHH.

Project administration: JHH, CHL, GKL, SJJ.

Writing—original draft: DHS.

Writing-review \& editing: DHS, HSS, TJK, HSP, YLC, WSK, LK, SHC, JSS, HJK, JHH, CHL, GKL, SJJ.

\section{Conflicts of Interest}

The authors declare that they have no potential conflicts of interest.

\section{REFERENCES}

1. Lynch TJ, Bell DW, Sordella R, et al. Activating mutations in the epidermal growth factor receptor underlying responsiveness of non-small-cell lung cancer to gefitinib. N Engl J Med 2004; 350: 2129-39.

2. Paez JG, Janne PA, Lee JC, et al. EGFR mutations in lung cancer: correlation with clinical response to gefitinib therapy. Science 2004; 304: 1497-500.

3. Mok TS, Wu YL, Thongprasert S, et al. Gefitinib or carboplatin-paclitaxel in pulmonary adenocarcinoma. N Engl J Med 2009; 361: 947-57.

4. Balak MN, Gong Y, Riely GJ, et al. Novel D761Y and common secondary T790M mutations in epidermal growth factor receptor-mutant lung adenocarcinomas with acquired resistance to kinase inhibitors. Clin Cancer Res 2006; 12: 6494-501.

5. Thress KS, Paweletz CP, Felip E, et al. Acquired EGFR C797S mutation mediates resistance to AZD9291 in non-small cell lung cancer harboring EGFR T790M. Nat Med 2015; 21: 560-2.

6. Sequist LV, Waltman BA, Dias-Santagata D, et al. Genotypic and histological evolution of lung cancers acquiring resistance to EGFR inhibitors. Sci Transl Med 2011; 3: 75ra26.

7. Sequist LV, Waltman BA, Dias-Santagata D, et al. Genotypic and histological evolution of lung cancers acquiring resistance to EGFR inhibitors. Sci Transl Med 2011; 3: 75ra26.

8. Yu HA, Arcila ME, Rekhtman N, et al. Analysis of tumor specimens at the time of acquired resistance to EGFR-TKI therapy in 155 patients with EGFR-mutant lung cancers. Clin Cancer Res 2013; 19: 2240-7.

9. Goss G, Tsai CM, Shepherd FA, et al. Osimertinib for pretreated EGFR Thr790Met-positive advanced non-small-cell lung cancer (AURA2): a multicentre, open-label, single-arm, phase 2 study. Lancet Oncol 2016; 17: 1643-52.

10. Yang JC, Ahn MJ, Kim DW, et al. Osimertinib in pretreated T790Mpositive advanced non-small-cell lung cancer: AURA study phase II extension component. J Clin Oncol 2017; 35: 1288-96.

11. Ballard P, Yates JW, Yang Z, et al. Preclinical comparison of osimertinib with other EGFR-TKIs in EGFR-mutant NSCLC brain metastases models, and early evidence of clinical brain metastases activity. Clin Cancer Res 2016; 22: 5130-40.

12. Diehl F, Schmidt K, Choti MA, et al. Circulating mutant DNA to assess tumor dynamics. Nat Med 2008; 14: 985-90.

13. Wan JCM, Massie C, Garcia-Corbacho J, et al. Liquid biopsies come of age: towards implementation of circulating tumour DNA. Nat Rev Cancer 2017; 17: 223-38.

14. Sholl LM, Aisner DL, Allen TC, et al. Liquid biopsy in lung cancer: a perspective from members of the Pulmonary Pathology Society. Arch Pathol Lab Med 2016; 140: 825-9.

15. Cobas EGFR Mutation Test v2, PMA 150047. FDA summary of safety and effectiveness data [Internet]. Silverspring: US Food and Drug Administration, 2016 [cited 2018 Jan 2]. Available from: https://www.accessdata.fda.gov/cdrh_docs/pdf15/P150047B.pdf.

16. Mino-Kenudson M. Cons: Can liquid biopsy replace tissue biopsy?: the US experience. Transl Lung Cancer Res 2016; 5: 424-7.

17. Ilie M, Hofman P. Pros: can tissue biopsy be replaced by liquid biopsy? Transl Lung Cancer Res 2016; 5: 420-3.

18. Mock TS, Carbone DP, Hirsch FR. IASLC atlas of EGFR testing in lung cancer. Aurora: International Association for the Study of Lung Cancer, 2017.

19. Alidousty C, Brandes D, Heydt C, et al. Comparison of blood collection tubes from three different manufacturers for the collection of cell-free DNA for liquid biopsy mutation testing. J Mol Diagn 2017; 19: 801-4.

20. Kang Q, Henry NL, Paoletti C, et al. Comparative analysis of circulating tumor DNA stability In K3EDTA, Streck, and CellSave blood collection tubes. Clin Biochem 2016; 49: 1354-60.

21. Fleischhacker M, Schmidt B, Weickmann S, et al. Methods for isolation of cell-free plasma DNA strongly affect DNA yield. Clin Chim Acta 2011; 412: 2085-8. 
22. Sorber L, Zwaenepoel K, Deschoolmeester V, et al. A comparison of cell-free DNA isolation kits: isolation and quantification of cellfree DNA in plasma. J Mol Diagn 2017; 19: 162-8.

23. Vendrell JA, Mau-Them FT, Beganton B, Godreuil S, Coopman P, Solassol J. Circulating cell free tumor DNA detection as a routine tool for lung cancer patient management. Int J Mol Sci 2017; 18: E264.

24. Thress KS, Brant R, Carr TH, et al. EGFR mutation detection in ctDNA from NSCLC patient plasma: a cross-platform comparison of leading technologies to support the clinical development of AZD9291. Lung Cancer 2015; 90: 509-15.

25. Reck M, Hagiwara K, Han B, et al. ctDNA determination of EGFR mutation status in European and Japanese patients with advanced NSCLC: the ASSESS study. J Thorac Oncol 2016; 11: 1682-9.

26. Bernabe R, Hickson N, Wallace A, Blackhall FH. What do we need to make circulating tumour DNA (ctDNA) a routine diagnostic test in lung cancer? Eur J Cancer 2017; 81: 66-73.

27. Qiu M, Wang J, Xu Y, et al. Circulating tumor DNA is effective for the detection of EGFR mutation in non-small cell lung cancer: a meta-analysis. Cancer Epidemiol Biomarkers Prev 2015; 24: 206-12.

28. Luo J, Shen L, Zheng D. Diagnostic value of circulating free DNA for the detection of EGFR mutation status in NSCLC: a systematic review and meta-analysis. Sci Rep 2014; 4: 6269.

29. Wu Y, Liu H, Shi X, Song Y. Can EGFR mutations in plasma or serum be predictive markers of non-small-cell lung cancer? A meta-analysis. Lung Cancer 2015; 88: 246-53.

30. Fassunke J, Thle MA, Lenze D, et al. EGFR T790M mutation testing of non-small cell lung cancer tissue and blood samples artificially spiked with circulating cell-free tumor DNA: results of a round robin trial. Virchows Arch 2017; 471: 509-20.

31. Haselmann V, Ahmad-Nejad P, Geilenkeuser WJ, et al. Results of the first external quality assessment scheme (EQA) for isolation and analysis of circulating tumour DNA (ctDNA). Clin Chem Lab Med 2018; 56: 220-8.

32. Oser MG, Niederst MJ, Sequist LV, Engelman JA. Transformation from non-small-cell lung cancer to small-cell lung cancer: molecular drivers and cells of origin. Lancet Oncol 2015; 16: e165-72.

33. Oxnard GR, Thress KS, Alden RS, et al. Association between plasma genotyping and outcomes of treatment with osimertinib (AZD9291) in advanced non-small-cell lung cancer. J Clin Oncol 2016; 34: 3375-82. 